\title{
Synthesis and Optical Properties of Co and Zn-Based Metal Oxide Nanoparticle Thin Films
}

\author{
E. Gungor ${ }^{a, *}$, T. Gungor ${ }^{a}$, D. Caliskan ${ }^{b}$ And E. OzBay $^{b}$ \\ ${ }^{a}$ Mehmet Akif Ersoy University, Department of Energy Systems Engineering, 15030 Burdur, Turkey \\ ${ }^{b}$ Bilkent University, Nanotechnology Research Center, 06800 Ankara, Turkey
}

\begin{abstract}
$\mathrm{ZnO}$, Co doped $\mathrm{ZnO}$ ( $\mathrm{ZnO}: \mathrm{Co}$ ) and $\mathrm{CoO}$ thin films were deposited on glass substrates by using the spark discharge technique with Zn-Zn, Zn-Co and Co-Co metal electrodes (tips). The structural and optical properties of the films were characterized by X-ray diffraction, scanning electron microscopy measurements and UV-Vis spectrometry. Cubic phase reflection of $\mathrm{CoO}$ (200) was observed in the samples containing Co. The size of nanoparticles had varied between $38 \mathrm{~nm}$ and $200 \mathrm{~nm}$ in $\mathrm{ZnO}$ thin films. When Co electrode was used, spherical structure had deteriorated and clusters of particles, with smaller radii, were observed. In addition, when Co-Co electrode pairs were used, various cavities with different sizes were formed. Especially, it was observed that the optical transmittance had generally increased with the decreasing spark (charge) voltage, while increasing with the number of sparks. The Co-containing samples were green in color and it was observed that the loss of transmission appears in a specific region in the Co-doped $\mathrm{ZnO}$ thin films due to characteristic $d$ - $d$ transition of $\mathrm{Co}^{2+}$ ions. The thickness of the films had decreased with the increasing number of sparks. In addition, the band gap energy, $E_{\mathrm{g}}$, evaluated by UV-Vis spectroscopy measurements has been shifted to higher wavelengths (red shift) for the $\mathrm{ZnO}$ :Co thin films.
\end{abstract}

DOI: 10.12693/APhysPolA.131.500

PACS/topics: 81.07.Bc, 78.67.Bf

\section{Introduction}

A variety of synthesis techniques have been the subject of numerous studies, since the composition, structure, size and size distribution of synthesized nanoparticles (NPs) influence the materials in terms of their mechanical, electrical, optical and magnetic properties, etc., depending on the employed technique. Among them, the spark discharge technique is a simple, compact, and a versatile method to grow nanoparticles from different types of materials. In addition, the synthesis can be performed at atmospheric pressure, offering a significantly more economical approach, in comparison with vacuum methods and has the potential of being scaled up. The method was first used by Schwyn in 1988 [1]. Subsequently, large number of research groups produced nano forms of carbon [2], carbon flakes [3], metals [4], metal oxide NPs $[5,6]$ and semiconductor Si nanoparticles [7]. In this method, depending on the charge voltage and separation of the electrodes, a spark of short duration between counter electrodes produces sufficient heat to evaporate some of the electrode material. Not only the deposition geometry but also the tip shapes are very important for depositing NPs in this method. Kumpika et al. have demonstrated how tip shapes and high voltages affect the NP's structure, as well as their size and size distribution [8].

Being both transparent and conductive, zinc oxide $(\mathrm{ZnO})$ has become the focus of many scientific studies

*corresponding author; e-mail: egungor@mehmetakif.edu.tr in the past twenty years. Nowadays, $\mathrm{ZnO}$ and related alloys, such as cobalt (Co) doped zinc oxide ( $\mathrm{ZnO}: \mathrm{Co}$ ), are some of the most promising candidates for diluted magnetic semiconductors. ZnO:Co deposition has been intensively studied because of its widespread applicability as a magnetic semiconductor [9-11]. Dopant atom can modify electrical, optical and magnetic properties of host structure. However, there must be a limitation of Co doping into the $\mathrm{ZnO}$ structure. Knowledge of this limit is important for technological applications. Apart from its magnetic properties, the optical transmittance and electrical conductivity of $\mathrm{ZnO}$ :Co may be useful for various applications. On the other hand, the carrier concentration has pronounced influences on the absorption edge in optical transmission spectra of epitaxial $\mathrm{ZnO}$ :Co films, in which both a blue-shift and a red-shift are observed. Moreover, structural properties of doped $\mathrm{ZnO}$ strongly depend on the growth and preparation conditions [12-15]. However, there is no classification of the variation of band gap with respect to the method used. This matter is still unclear.

In order to contribute to clarification of the uncertainty in band gap shift, we have fabricated $\mathrm{ZnO}$ :Co films deposited using the spark discharge system. Thus, in this work, we have investigated the sense and degree of band edge shift, that would support blue- or red-shift. Combinations of $\mathrm{Zn}-\mathrm{Zn}, \mathrm{Zn}-\mathrm{Co}$, and Co-Co tips in vertical spark geometry were used as the source of metal. Then, the optical and structural properties of metal NPs fabricated on glass substrates by the spark discharge system were investigated. The structural and morphological properties of the films were characterized by XRD and SEM. 


\section{Materials and methods}

The microscope glass $\left(10 \times 10 \times 1 \mathrm{~mm}^{3}\right)$ was used as the substrate. High purity $(99.97 \%)$ zinc $(R=0.38 \mathrm{~mm})$ and cobalt $(R=0.25 \mathrm{~mm})$ wires were used as source materials. The nanoparticles were fabricated by a spark discharge system in the vertical geometry. The sparking occurred when a $0.2 \mu \mathrm{F}$ capacitor connected to the combination of Zn-Zn, Zn-Co, and Co-Co tips by the rotating switch was charged to $4 \mathrm{kV}$ and $7 \mathrm{kV}$. The experiment was done repeatedly for 50 and 100 times with the sparking time of $3 \mathrm{~s} /$ spark at atmospheric pressure in ambient air. Due to high voltage, discharge etches the tips during the process, and thus, the distance (gap) between the tips changes, which can be compensated by a linear actuator controlled by a stepper motor driver unit.

Crystal structure was investigated by X-ray diffraction (Bruker D8 ADVANCE) using $\mathrm{Cu} \mathrm{K}_{\alpha_{1}}$ radiation $(\lambda=$ $1.5406 \AA)$. The microstructures of the samples were investigated using a Zeiss SEM column, equipped with an energy dispersive inlens detector. The optical transmittance measurements of the samples were carried out at room temperature using a T70 Model spectrophotometer (PG Instrument) in the wavelength range of 300-900 nm. A special mask was centered on the spark-affected region.

\section{Results and discussion}

The XRD patterns of $\mathrm{ZnO}, \mathrm{ZnO}$ : $\mathrm{Co}$ and $\mathrm{CoO}$ thin films at room temperature and reference peak positions are presented in Fig. 1. The results indicate that preferential $c$-axis (002) peaks of hexagonal wurtzite structure of $\mathrm{ZnO}$ are observed for $\mathrm{Zn}-\mathrm{Zn}$ electrodes. The peaks at $36.25^{\circ}$ and $36.50^{\circ}$ are (101) and (111) peaks for $\mathrm{ZnO}$ and $\mathrm{CoO}$, respectively. In contrast, when $\mathrm{Zn}$-Co electrode pairs were used, the peaks at $42.33^{\circ}$ Bragg angle of cobalt oxide (200) and at $36.40^{\circ}$ Bragg angle of $\mathrm{ZnO}(002)$ were observed. When the spark voltage was increased, the (200) peak intensities had increased. In the films, the mixture of hexagonal wurtzite and cubic structures were observed. When Co-Co electrode pair was used, (111) and (200) peaks have occurred, predominantly.

The SEM analysis was carried out at the center of the spark-affected area for the vertical geometry of the tips in spark discharge system for $7 \mathrm{kV}$ and a spark number of 100. Figure 2a shows that the diameters of NPs are about 38-200 nm for $\mathrm{Zn}-\mathrm{Zn}$ electrodes. When the $\mathrm{Zn}-\mathrm{Co}$ electrodes were used, a mixture of nanoparticles was observed. $\mathrm{ZnO}$ :Co sample consists of grains, interconnected in agglomerated clusters. The grain size of $\mathrm{ZnO}$ :Co sample, about $85 \mathrm{~nm}$, is smaller than that of the $\mathrm{ZnO}$ sample (Fig. 2b). This SEM image shows that some of the NPs were agglomerated as the linear ridges with linear space formations on the film surface. When the Co-Co electrodes were used, sharp and non-spherical particles were observed on the film surface and there was a smoother surface. When the Zn-Co electrodes were used under $7 \mathrm{kV}$ during the process of 50 sparks, the surface of the $\mathrm{ZnO}$ :Co thin film was flat and dense. However, the film
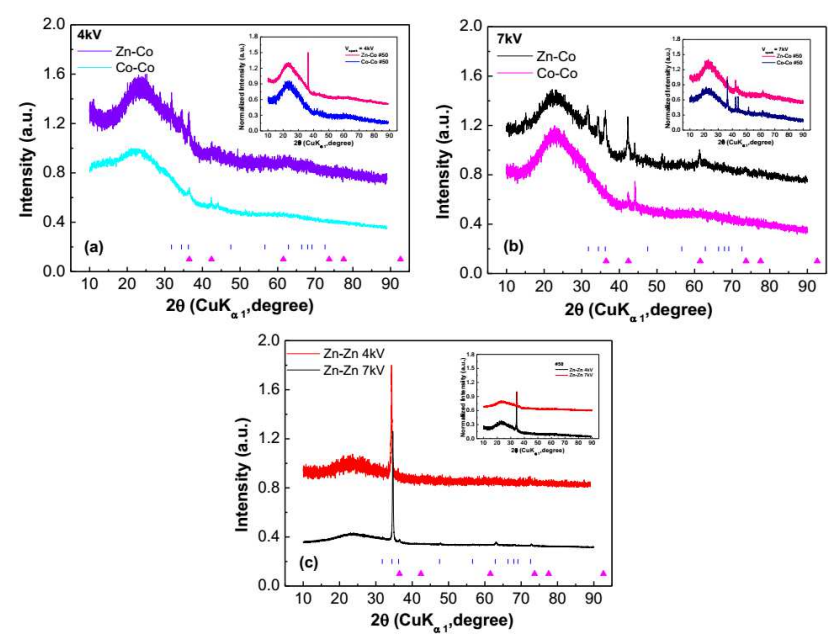

Fig. 1. X-ray diffraction patterns of $\mathrm{ZnO}$ :Co, cobalt oxide and zinc oxide NPs, obtained after 100 sparks when $V_{\text {spark }}$ was (a) $4 \mathrm{kV}$, (b) $7 \mathrm{kV}$ and (c) both $4 \mathrm{kV}$ and $7 \mathrm{kV}$ for $\mathrm{ZnO}$ thin films. "l" and " $\Delta$ " symbols indicate the reference for $\mathrm{ZnO}$ (JCPDS 36-1451) and CoO (JCPDS 43-1004), respectively.
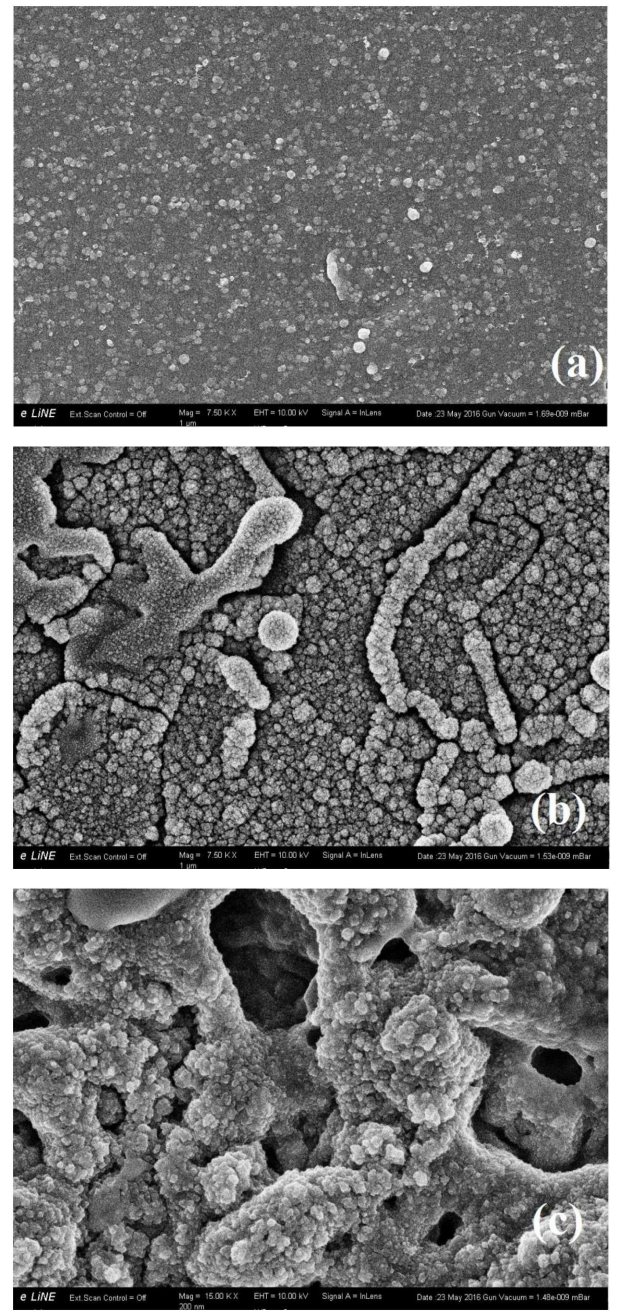

Fig. 2. SEM images for the samples obtained with (a) $\mathrm{Zn}-\mathrm{Zn}$ electrodes at $7 \mathrm{kV}$, (b) Zn-Co electrodes at $7 \mathrm{kV}$ and (c) Co-Co electrodes at $4 \mathrm{kV}$ sparking voltage. 
surface obtained from Co-Co electrodes seems to be coated by NPs of approximately $50 \mathrm{~nm}$ diameter and some cavities of different sizes were observed (Fig. 2c).

The experimental optical transmission spectra of thin films are shown in Fig. 3a and b. The effects of sparking voltage $\left(V_{\text {spark }}\right)$ and number are clearly observed in the optical transmission spectra. The increase of spark number increases the optical transmittance, except for Zn-Co electrode pairs, for $4 \mathrm{kV}$ and a sparking number of 50. In addition, when the cobalt electrode was used for the Zn-Co and Co-Co electrode configuration, a region of green color was observed in the center of the films. The thickness of thin films decreases with increasing number of sparks.

Besides, characteristic features of $d$ - $d$ transition of $\mathrm{Co}^{2+}$ ions are observed in the transmission spectrum of the $\mathrm{ZnO}$ :Co thin films (Zn-Co electrode pairs, $V_{\text {spark }}=$ $7 \mathrm{kV}, n=100)$. These transition peaks are centered at $562 \mathrm{~nm}(2.21 \mathrm{eV}), 611 \mathrm{~nm}(2.03 \mathrm{eV})$ and $647 \mathrm{~nm}(1.92 \mathrm{eV})$. This behavior is also observed for the $\mathrm{ZnO}$ :Co thin films prepared using ultrasonic spray pyrolysis technique [12].

Point-wise unconstrained minimization algorithm (PUMA) [16] is one of the methods that can use wavelength-dependent optical transmittance values for the determination of the optical constants, such as film thickness, refractive index and optical band gap.
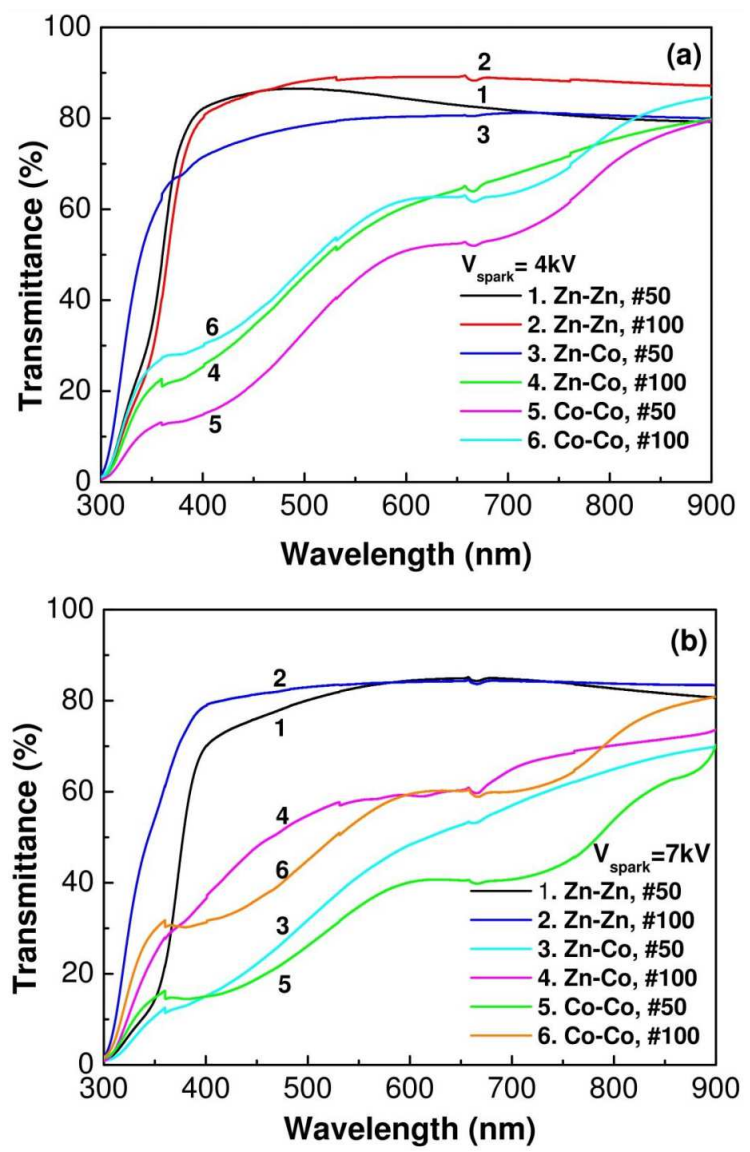

Fig. 3. Optical transmission spectra of the films prepared using (a) $4 \mathrm{kV}$ and (b) $7 \mathrm{kV}$ sparking voltage.
Optical band gaps of thin films can be determined using the relation, $E_{g}(\mathrm{eV})=1240.8 / \lambda_{\text {inf }}$ where $\lambda_{\text {inf }}$ is defined as the inflexion wavelength, at which the second derivative of the transmission curve is zero. $E_{g}$ values were found to be around $3.13-3.18 \mathrm{eV}$ for $\mathrm{ZnO}, 2.6-2.8 \mathrm{eV}$ for $\mathrm{ZnO}$ : $\mathrm{Co}$ and $2.50-2.55 \mathrm{eV}$ for $\mathrm{CoO}$ thin films.

\section{Conclusions}

$\mathrm{ZnO}$, as well as $\mathrm{ZnO}$ : $\mathrm{Co}$ and $\mathrm{CoO}$ thin films were deposited by the spark discharge system employing $\mathrm{Zn}$ and Co metal wires in a combination of Zn-Zn, Zn-Co and CoCo electrode pairs. Structural analysis of samples has shown that the intensive (200) peak of cobalt oxide cubic structure and the intensive (002) peak of $\mathrm{ZnO}$ hexagonal wurtzite structure had coexisted when the Zn-Co electrodes were used at the same time. Thus, the mixture of cubic and hexagonal wurtzite phases was obtained as expected. The peak intensities increase with the spark voltage. The NPs are about $38-200 \mathrm{~nm}$ in diameter for $\mathrm{ZnO}$ thin films. When Co was used as electrode, spherical structure deteriorated and smaller radius clusters of particles were observed. In addition, for Co-Co electrode pairs, some cavities of different sizes were observed. The optical transmittance generally increases with decreasing voltage, whereas it increases with the number of sparks. This is also related to the decrease of the film thickness. The band gap energy, $E_{\mathrm{g}}$, evaluated by $\mathrm{UV}-\mathrm{Vis}$ spectroscopy, was $3.13-3.18 \mathrm{eV}$ for $\mathrm{ZnO}$, while it was $2.6-2.8 \mathrm{eV}$ for $\mathrm{ZnO}$ : $\mathrm{Co}$ and $2.50-2.55 \mathrm{eV}$ for $\mathrm{CoO}$ thin films. The optical gap of $\mathrm{ZnO}$ :Co is shifted to higher wavelengths (i.e. red-shifted) with Zn-Co electrodes as the source materials. The experimental results show that structural and optical properties of the investigated samples are significantly affected by the spark number and applied high voltage.

\section{Acknowledgments}

This research has been supported by the Scientific Research Unit of Mehmet Akif Ersoy University. Project Number: 110-NAP-10, 0172-NAP-13, 0173-NAP-13, 0324-NAP-16 and 0356-NAP-16.

\section{References}

[1] S. Schwyn, E. Garwin, A. Schmidtott, J. Aerosol Sci. 19, 639 (1988).

[2] H. Horvath, M. Gangl, J. Aerosol Sci. 34, 1581 (2003).

[3] S. Thongtem, P. Singjai, T. Thongtem, S. Preyachoti, Mat. Sci. Eng.: A 423, 209 (2006).

[4] N.S. Tabrizi, M. Ullmann, V.A. Vons, U. Lafont, A. Schmidt-Ott, J. Nanopart. Res. 11, 315 (2009).

[5] N.S. Tabrizi, Q. Xu, N.M. van der Pers, A. SchmidtOtt, J. Nanopart. Res. 12, 247 (2010).

[6] J.T. Kim, J.S. Chang, J. Electrostat. 63, 911 (2005).

[7] V.A. Vons, L.C.P.M. de Smet, D. Munao, A. Evirgen, E.M. Kelder, J. Nanopart. Res. 13, 4867 (2011). 
[8] T. Kumpika, W. Thongsuwan, P. Singjai, Thin Solid Films, 516, 5640 (2008).

[9] T. Dietl, H. Ohno, F. Matsukura, J. Cibert, D. Ferrand, Science 287, 1019 (2000).

[10] H.J. Lee, S.Y. Jeong, C.H. Cho, C.H. Park, Appl. Phys. Lett. 81, 4020 (2002).

[11] P. Cao, Y. Bai, Adv. Mater. Res. 9, 781 (2013).

[12] E. Gungor, T. Gungor, D. Caliskan, A. Ceylan, E. Ozbay, Appl. Surf. Sci. 318, 309 (2014).

[13] S. Lee, B.S. Kim, Y.C. Cho, J.M. Shin, S.W. Seo, C.R. Cho, I. Takeuchi, S.Y. Jeong, Curr. Appl. Phys. 13, 2005 (2013).
[14] Y.C. Cho, S.J. Kim, S. Lee, S.J. Kim, C.R. Cho, H.H. Nahm, C.H. Park, I.K. Jeong, S. Park T.E. Hong, S. Kuroda, S.Y. Jeong, Appl. Phys. Lett. 95, 172514 (2009).

[15] Y.C. Cho, S. Lee, H.H. Nahm, S.J. Kim, C.H. Park, S.Y. Lee, S.K. Kim, C.R. Cho, H. Koinuma, S.Y. Jeong, Appl. Phys. Lett. 100, 112403 (2012).

[16] E.G. Birgin, I. Chambouleyron, J.M. Martinez, J. Comput. Phys. 151, 862 (1999). 